\title{
A epêntese no português brasileiro em uma perspectiva multirrepresentacional
}

Maria Mendes Cantoni ${ }^{a}$

\section{RESUMO}

Este trabalho trata da epêntese no português brasileiro e sua interação com o acento da palavra. Em especial, avalia-se o caráter gradiente da epêntese, tanto em termos lexicais e estruturais, quanto em termos fonéticos. A principal contribuição deste trabalho é discutir o fenômeno da epêntese sob uma perspectiva teórica inovadora, com base na Fonologia de Laboratório e nos Modelos Multirrepresentacionais. Dados coletados experimentalmente indicam que há gradiência lexical na implementação da epêntese, bem como do fenômeno de acentuação de vogais epentéticas. Verificou-se ainda que as vogais epentéticas acentuadas apresentam duração intermediária entre as vogais epentéticas átonas e as vogais correspondentes plenas, havendo portanto gradiência fonética na implementação do fenômeno. Sugere-se neste estudo que os dados levantados dão suporte a uma visão multidimensional das representações sonoras e que o sistema linguístico encontra-se organizado em redes de relações.

Palavras-chave: Epêntese, Acento, Fonologia de Uso, Português Brasileiro

\footnotetext{
${ }^{a}$ UFMG - Universidade Federal de Minas Gerais. programa de Pós-Doutorado realizado junto ao Poslin. mmcantoni@gmail.com
} 
A epêntese, fenômeno que consiste na inserção de uma vogal em uma palavra, acontece em diversas línguas do mundo, mas apresenta certas particularidades que variam de língua para língua. As razões que desencadeiam a epêntese são tipicamente fonotáticas ou métricas. Há diferenças na qualidade das vogais epentéticas de língua para língua. Além disso, em uma mesma língua, a vogal epentética pode ser sempre a mesma, ou variar de acordo com o ambiente sonoro no qual é inserida. Outro aspecto importante diz respeito ao ponto de inserção da vogal, que pode ocorrer antes, depois ou entre determinados sons (HALL, 2011).

Neste estudo, trataremos da epêntese no português brasileiro e sua interação com o acento da palavra. Em especial, pretendemos avaliar o caráter gradiente da epêntese, tanto em termos lexicais e estruturais, quanto em termos fonéticos. A principal contribuição deste trabalho é discutir o fenômeno da epêntese sob uma perspectiva teórica inovadora, com base na Fonologia de Laboratório e nos Modelos Multirrepresentacionais.

Este artigo apresenta a seguinte organização: a primeira seção resenha achados da literatura pertinentes ao tema; a segunda seção descreve a perspectiva teórica adotada; na terceira seção, é apresentada a metodologia; a quarta seção é dedicada à análise e discussão dos resultados; na quinta seção, são propostas algumas considerações finais, seguidas das referências bibliográficas.

\section{Revisão da literatura}

\subsection{A epêntese no português brasileiro}

No português brasileiro, a epêntese é opcional e, de

1 Cs são consoantes envolvidas, Vep é a vogal inserida, marca as divisões silábicas e \# indica fronteira de palavra. Quando relevantes, as vogais epentéticas serão marcadas por negrito e as sílabas acentuadas ou tônicas serão marcadas por'. modo geral, ocorre (1) em certos grupos de consoantes que se encontram em sílabas diferentes, (2) depois de consoantes obstruintes em coda em final de palavra, (3) em alguns grupos de consoantes na mesma sílaba em início de palavra e (4) antes de nasal palatal em inicio de palavra, como mostram os seguintes exemplos:

(1) C.C $\sim$ CVep.C : optar, dignidade, advogado, rítmico, psicologia, impactar 
(2) C\# .CVep\# : internet, hot dog

(3) \#CC \#VepC.C : spam, status

(4) \#C \#VepC : nhoque

Observa-se que a vogal epentética pode ocorrer antes (34), depois (2) ou entre (1) as consoantes envolvidas na epêntese. Em todos os casos, uma nova sílaba é criada pela inserção da vogal, com alteração da posição fonotática da consoante: de coda para onset (1-2) ou de onset ramificado para coda (3).

Além dos casos mencionados acima, alguns dialetos apresentam um caso particular de epêntese, em que são formados ditongos em alternância com um monotongo. Nesse caso, a vogal epentética é inserida na última sílaba de uma palavra, se a mesma for acentuada e terminada por [s]:

(5) `V[s]\# ‘VVep[s]\# : paz, xadrez

Embora para os modelos teóricos tradicionais os fenômenos (1-4) e, por vezes, (5) são classificados igualmente como epêntese, em modelo multirrepresentacionais, cada um desses fenômenos reflete uma trajetória específica do sistema sonoro da língua.

Neste estudo, iremos enfocar o caso de epêntese (1). Os casos (2-4) são muito específicos e se restringem a um pequeno número de palavras da língua e ocorrem principalmente em neologismos (empréstimos, siglas, etc.). O caso (5), por outro lado, é marcadamente sujeito a variação dialetal. Já o caso (1) é mais abrangente, por razões segmentais e métricas: é desencadeado por uma maior variedade de consoantes (certas obstruintes seguidas de qualquer obstruinte na silaba seguinte). Historicamente, o caso (1) é característico de um número de palavras muito antigas na língua - e pode ocorrer em qualquer palavra que apresentar contexto propício, independentemente de classe da palavra, número de sílabas ou origem. O contexto de ocorrência da epêntese do caso (1) é qualquer grupo consonantal do tipo C1.C2, em que ambas estão em sílabas diferentes e C1 é uma oclusiva ou [f] e C2 é uma obstruinte; ou C1 é [m] e C2 é [n].

Os dados coletados por Collischonn (2002) mostram que a epêntese é mais favorecida em sílabas pré-tônicas do que em 
sílabas pós-tônicas. Há favorecimento do fenômeno também quando C1 é uma alveolar e quando C2 é uma fricativa não-sibilante ou uma nasal. Por outro lado, a epêntese é desfavorecida quando $\mathrm{C} 1$ é uma velar. A autora atribui o baixo índice de ocorrência de epêntese quando em grupos do tipo $\mathrm{C}+[\mathrm{s}]$ à existência na língua de africadas com essa mesma estrutura sonora: se[t $\mathrm{t} i]$, mé[dzi]co. A autora aponta ainda as restrições fonotáticas de sonoridade como possível explicação para o favorecimento da epêntese em grupos em que há oclusiva seguida de nasal.

A vogal epentética no português brasileiro, em geral, compartilha propriedades compatíveis com as características fonéticas de uma vogal anterior alta [i] ou [I], e, mais raramente, com as de um [e]: [pneu] [pineu] $\sim$ [pineu] $\sim$ [peneu]. A alternância de [i] com [I] e [e] é uma característica do sistema sonoro do português brasileiro e acontece prioritariamente em sílabas átonas: $\mathrm{m}[\mathrm{e}]$ 'nino $\sim \mathrm{m}[\mathrm{i}]$ 'nino; chequ[e] $\sim$ chequ[i] $\sim$ chequ[I].

\subsection{A acentuação de vogais epentéticas}

Neste estudo, avaliamos, em especial, o fenômeno de acentuação de vogais epentéticas. Como já apontava Câmara Jr. (1970), em verbos com grupo de obstruintes na última sílaba da raiz, especificamente nas flexões em que a última vogal da raiz recebe o acento (o que acontece nas flexões de presente, exceto na $1^{\mathrm{a}}$ e $2^{\mathrm{a}}$ pessoas do plural), verifica-se que opcionalmente a vogal epentética pode ser acentuada: e.g. (eu) 'o[pt]o $\sim$ 'o[pit]o o'[pit]o.

Em estudos anteriores, foi observado que a sequência [ks] tipicamente não apresenta epêntese (CANTONI, 2009) e, ainda, que verbos contendo a sequência [ks] na última sílaba da raiz não estariam sujeitos ao fenômeno de acentuação de vogais epentéticas (CANTONI; SILVA, 2008). Entretanto, verificou-se que, em condições específicas, verbos contendo outras sequências de consoantes podem apresentar vogal epentética acentuada, mas nomes não podem.

Neste estudo, avaliaremos o fenômeno de acentuação da vogal epentética, que ocorre no português brasileiro exclusivamente em certas flexões de formas verbais. Argumentaremos que a emergência de vogais epentéticas acentuadas no sistema 
sonoro do português surgiu a partir da interação em rede entre padrões de variação envolvendo vogais foneticamente semelhantes $([\mathrm{i}] \sim[\mathrm{I}] \sim[\mathrm{e}])$ e as redes de relação entre o plano sonoro e o morfológico decorrentes dos padrões acentuais da língua.

Na morfologia verbal, a relação entre a vogal epentética e o acento tônico é diferente da morfologia nominal. Enquanto a vogal epentética não pode ser acentuada na morfologia nominal (*dig[i]no), ela pode receber acento na morfologia verbal. Por exemplo, em um verbo como adaptar, a vogal epentética ocorre entre as consoantes obstruintes, adap [i]tar. Neste caso, o acento recai sobre a marca de infinitivo -ar e não seria esperado que a vogal epentética recebesse o acento tônico. Entretanto, há casos em que a última vogal da raiz verbal deve receber o acento tônico, como é o caso da primeira pessoa do presente. Portanto, em um verbo como adaptar, espera-se que na $1^{a}$ pessoa do presente o acento ocorra na vogal que precede " $p$ ". De outra parte, observamos que o acento pode ocorrer na última vogal da raiz ou pode ocorrer na vogal epentética: (eu) adapto $\sim($ eu $)$ adap [i]to $\sim($ eu) adap[i]to. No caso de (eu) adapto, o acento tônico é atribuído à última vogal da raiz e o padrão acentual paroxítono é mantido. No caso de (eu) adap [i]to o acento é atribuído à última vogal da raiz, mas o padrão acentual passa a ser proparoxítono. No caso de (eu) adap[i]to, a vogal epentética é acentuada e o padrão acentual paroxítono é mantido. $\mathrm{O}$ conflito ocorre entre o padrão acentual e a camada segmental da forma verbal.

\section{Perspectiva teórica}

A perspectiva teórica adotada neste estudo se baseia em modelos multirrepresentacionais, como a Fonologia de Uso (BYBEE, 2001, 2010), o Modelo de Exemplares (JOHNSON, 1997; PIERREHUMBERT, 2001a) e os Sistemas Dinâmicos (ELLIS; LARSEN-FREEMAN, 2009). Procurou-se demonstrar que a emergência de novos padrões sonoros na morfologia verbal do português brasileiro, como as vogais epentéticas acentuadas, reflete a auto-organização gramatical que propicia a estabilidade e dinamicidade inerente às línguas naturais (BYBEE, 2001, 2010; ELLIS; LARSEN-FREEMAN, 2009). 
Os modelos multirrepresentacionais defendem que a gramática emerge e é moldada pela experiência com o mundo e com a linguagem (BARLOW; KEMMER, 2000). Como consequência da centralidade conferida ao uso da linguagem, a frequência de uso desempenha um papel fundamental para a construção da gramática e das unidades linguísticas (PIERREHUMBERT, 2001a). Há dois tipos de frequência: frequência de tipo e frequência de ocorrência. A frequência de tipo indica a contagem de cada padrão em particular. A frequência de ocorrência indica a contagem de um padrão determinado (ou tipo) em um corpus qualquer. A frequência tem impacto na organização gramatical e o exame de efeitos de frequência indicam trajetórias de mudanças nas línguas naturais.

Os modelos multirrepresentacionais assumem que representações linguísticas são múltiplas e detalhadas, sendo compostas por informações redundantes e mesmo não linguísticas (JOHNSON; MULLENIX, 2009). Com relação à dimensão sonora, estudos demonstram que o detalhe fonético fino exerce um papel fundamental no processamento linguístico (HAWKINS, 2003). O exame do detalhe fonético indica que há gradiência na implementação de padrões sonoros através do léxico.

Modelos multirrepresentacionais assumem que as representações linguísticas são conectadas em redes complexas, baseadas em similaridade fonética e semântica, cujo funcionamento se baseia em parâmetros probabilísticos e a partir das quais emergem padrões abstratos - esquemas morfológicos, sintáticos, etc. (PIERREHUMBERT, 2001a, 2001b). Em uma perspectiva multirrepresentacional, padrões morfológicos são interpretados como abstrações em níveis variados de complexidade (esquemas), que emergem do uso linguístico, interagem com a dimensão fonológica e estão sujeitos a efeitos de frequência (BYBEE, 1985). Os fenômenos avaliados neste estudo, que se referem à interação entre o acento lexical e a morfologia verbal no $\mathrm{PB}$, podem ser analisados com sucesso a partir de redes complexas, que modelam a emergência de mecanismos acentuais diferenciados para verbos e nomes.

\section{Metodologia}

Foi realizado um experimento com o propósito avaliar as características da vogal epentética acentuada. Esperava-se que 
alguns informantes iriam apresentar ocorrências de formas verbais em que o acento recairia sobre a vogal epentética na última sílaba da raiz, como (eu) óp [i]to. Procurou-se responder às seguintes perguntas:

a) Dentre os verbos analisados, quais favorecem e quais desfavorecem a epêntese?

b) Quais verbos favorecem a acentuação da vogal epentética?

c) Qual a natureza fonética das vogais epentéticas acentuadas, em comparação com as vogais plenas acentuadas?

Foram testados 10 falantes nativos do português brasileiro, no dialeto de Belo Horizonte, entre 20 e 50 anos, sendo cinco homens e cinco mulheres, todos com a escolaridade intermediária (até o Ensino Médio). Na tarefa proposta, os informantes eram levados a pronunciar uma forma verbal propícia ao fenômeno (i.e. contendo grupo de obstruintes e acento na última sílaba da raiz). Para isso, foi utilizado um paradigma de pergunta-resposta, em que um entrevistador fazia uma pergunta ao informante usando o verbo de interesse no pretérito perfeito, com flexão de $3^{\text {a }}$ pessoa do singular (de forma que o acento recaísse na vogal da desinência verbal e não influenciasse a resposta do informante). Em seguida, o informante deveria responder usando o mesmo verbo, no presente do indicativo, $1^{\mathrm{a}}$ pessoa do singular (de forma que o acento incidisse na última vogal da raiz):

Entrevistador: Você já

Informante: Eu sempre

Cada sessão de coleta de dados foi iniciada por um breve treinamento, em que o entrevistador utilizava o mesmo modelo de pergunta-resposta, mas com outros verbos, não relacionados ao estudo, para esclarecer aos informantes o que deveria ser feito.

Foram apresentados, ao todo, 14 estímulos, contendo seis distratores e oito itens de teste. Foram testados cinco itens com contexto favorável à ocorrência de vogal epentética acentuada: (eu) ritmo, indigno, compacto, adapto, opto. Foram testados tam- 
bém os itens acredito, digo e opino, que apresentam uma vogal [i] acentuada não epentética (ou plena) e serviram para fins de comparação com as vogais epentéticas. Pretendia-se, assim, verificar acusticamente semelhanças e diferenças na produção dos dois tipos de sons vocálicos.

Os sons de interesse foram segmentados, anotados e medidos por meio do programa Praat (BOERSMA; WEENINK, 2013). A segmentação e a anotação foram realizadas manualmente, ao passo que, para as medições, foram utilizados dois scripts: calculate-segment-durations (LENNES, 2002), para extrair a duração das vogais [i], das vogais tônicas e de cada palavra, e General vowel acoustics script for Praat (DICANIO, 2013), para obter os valores de formantes das vogais [i]. Os dados coletados e as medidas obtidas foram avaliados gráfica e estatisticamente por meio do ambiente R (R Development Core Team, 2011).

\section{Análise e discussão dos resultados}

Neste estudo, foram avaliados os valores de duração das vogais [i] plenas acentuadas; das vogais epentéticas átonas e das vogais epentéticas acentuadas. Os valores absolutos de duração obtidos nas medições foram transformados em valores relativos, dividindo-os pela duração total da respectiva palavra.

Os resultados apontam para a existência de variação na atribuição do acento a vogais epentéticas, tanto em relação ao comportamento de cada indivíduo, quanto em relação aos itens testados. Alguns falantes demonstraram dúvidas e hesitação no momento de realizar os verbos com contexto propício à acentuação da vogal epentética.

A seguir, apresentamos os resultados obtidos, procurando responder as perguntas de pesquisa levantadas na metodologia, retomadas por conveniência:

a) Dentre os verbos analisados, quais favorecem e quais desfavorecem a epêntese?

b) Quais verbos favorecem a acentuação da vogal epentética?

c) Qual a natureza fonética das vogais epentéticas acentuadas, em comparação com as vogais plenas acentuadas? 


\subsection{Condicionamento lexical da epêntese}

Dentre os verbos analisados, buscou-se avaliar se eles possivelmente favoreceriam ou desfavoreceriam a epêntese. A Fig. 1, a seguir, mostra os valores percentuais de epêntese para cada verbo testado. Como se pode verificar, alguns verbos, como "indigno", "opto" e "ritmo", apresentam altos índices de ocorrência de epêntese e parecem favorecer o fenômeno, ao passo que outros, como "adapto" e "compacto", apresentam índices menores de epêntese e, portanto, parecem favorecer menos o fenômeno. Além disso, observa-se que os verbos apresentam valores diferenciados de epêntese.

Figura 1 - Índices de epêntese para cada verbo testado

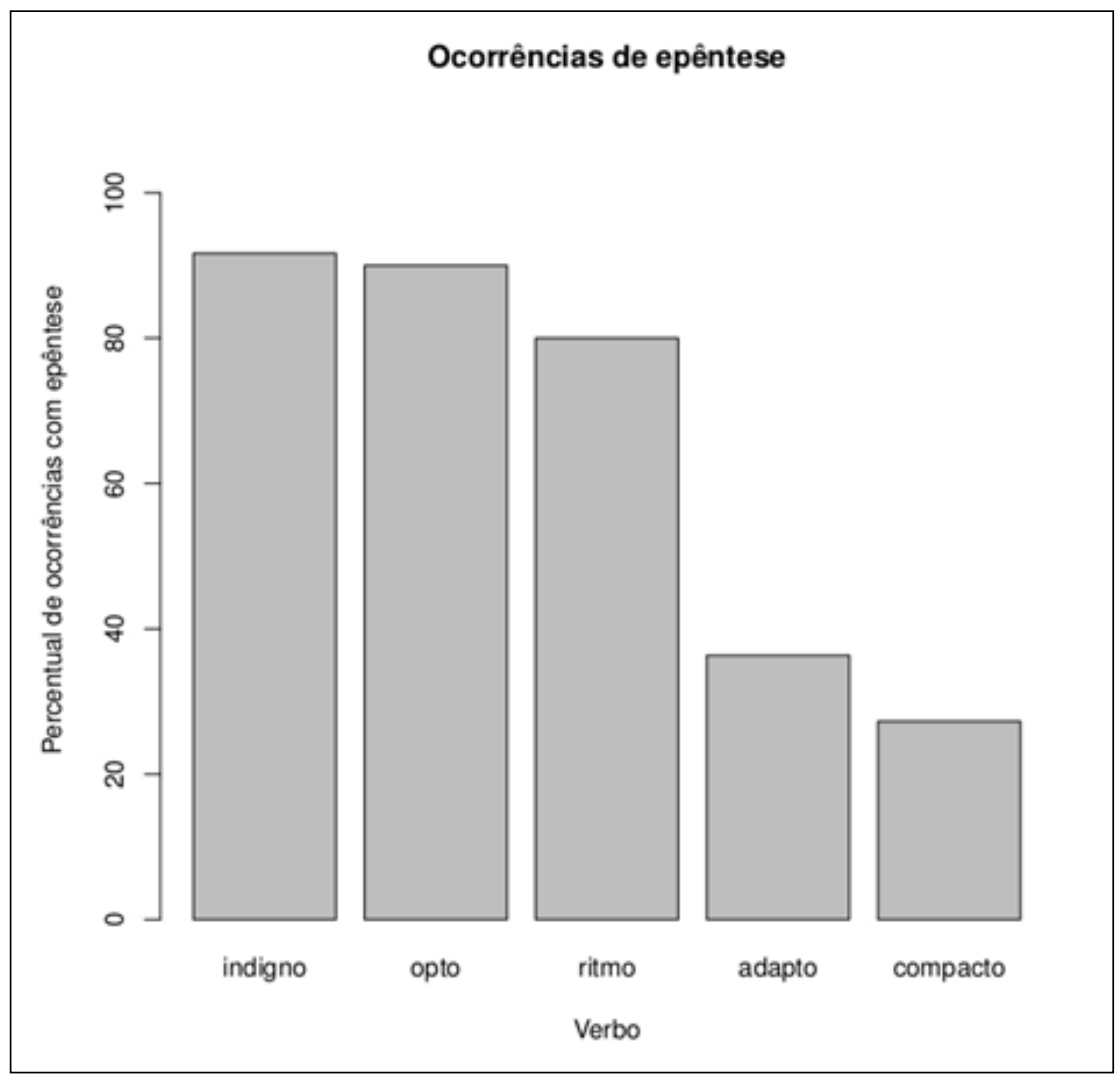

O teste qui-quadrado aplicado aos dados para testar a independência das variáveis "verbo" e "ocorrência de epêntese" confirma a tendência mostrada pela Fig. 1, apontando que a ocorrência de epêntese não é estatisticamente igual para cada 
um dos verbos testados $\left(\chi^{2}=18,289, d f=4, p=0,001\right)$. Ou seja, os verbos comportam-se de forma diferente com relação à epêntese, o que sugere uma implementação gradual do fenômeno.

\subsection{Condicionamento lexical da acentuação de vogais epentéticas}

Considerando os verbos testados, procurou-se então avaliar se eles possivelmente favoreceriam ou desfavoreceriam a acentuação de vogais epentéticas. A Fig. 2, a seguir, mostra os valores percentuais de vogal epentética acentuada para cada verbo testado. Como se pode verificar, os índices de acentuação de vogal epentética são médios ou altos para todos os verbos, que parecem favorecer o fenômeno. Alguns, como "adapto", "indigno" e "opto", apresentam índices de ocorrência mais elevados que outros, como "compacto" e "ritmo".

Figura 2 - Índices de acentuação de vogal epentética para cada verbo testado

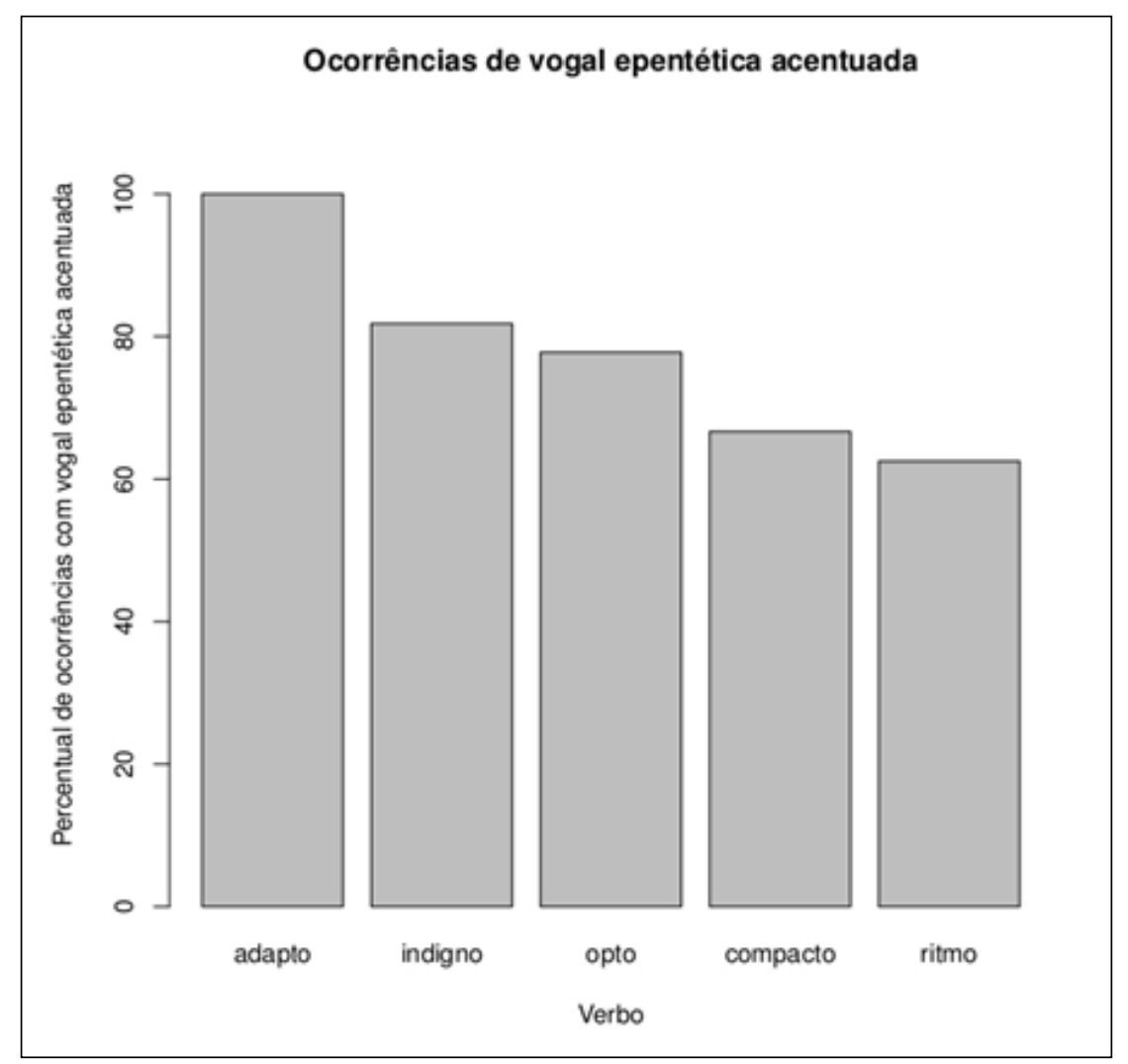


O teste qui-quadrado aplicado aos dados para testar a independência das variáveis "verbo" e "ocorrência de vogal epentética acentuada" não foi estatisticamente significativo $\left(\chi^{2}=2,483, \mathrm{df}=4, \mathrm{p}=0,647\right)$, não sendo possível, portanto, afirmar que os verbos testados se comportam de forma diferenciada com relação ao fenômeno. Contudo, o teste qui-quadrado foi significativo para testar a acentuação das vogais epentéticas $\left(\chi^{2}=10,314, \mathrm{df}=1, \mathrm{p}=0,001\right)$ e mostra que, dadas as condições propícias, verbos tendem a apresentar as vogais epentéticas acentuadas, confirmando a ampla ocorrência do fenômeno mostrada pela Fig. 2.

\subsection{Natureza fonética das vogais epentéticas}

Para avaliar a natureza fonética das vogais epentéticas acentuadas em relação às epentéticas átonas e vogais plenas, foi considerada a propriedade de duração. Estudos anteriores mostram que as vogais epentéticas tipicamente apresentam menor duração que as vogais plenas (CRISTÓFARO SILVA; ALMEIDA, 2006; SILVEIRA; SEARA, 2009), contudo, tanto as epentéticas quanto as plenas apresentam variação duracional e podem até mesmo ser omitidas. Os estudos mencionados avaliaram somente vogais epentéticas átonas. Procurou-se, neste estudo, avaliar as propriedades de duração das vogais epentéticas acentuadas, em comparação com outras vogais correspondentes átonas e plenas. A FIG. 3, a seguir, mostra os valores de duração para cada grupo de [i]: plenos, epentéticos átonos e epentéticos acentuados. 
Figura 3 - Valores relativos de duração para [i]s plenos, epentéticos átonos e epentéticos acentuados

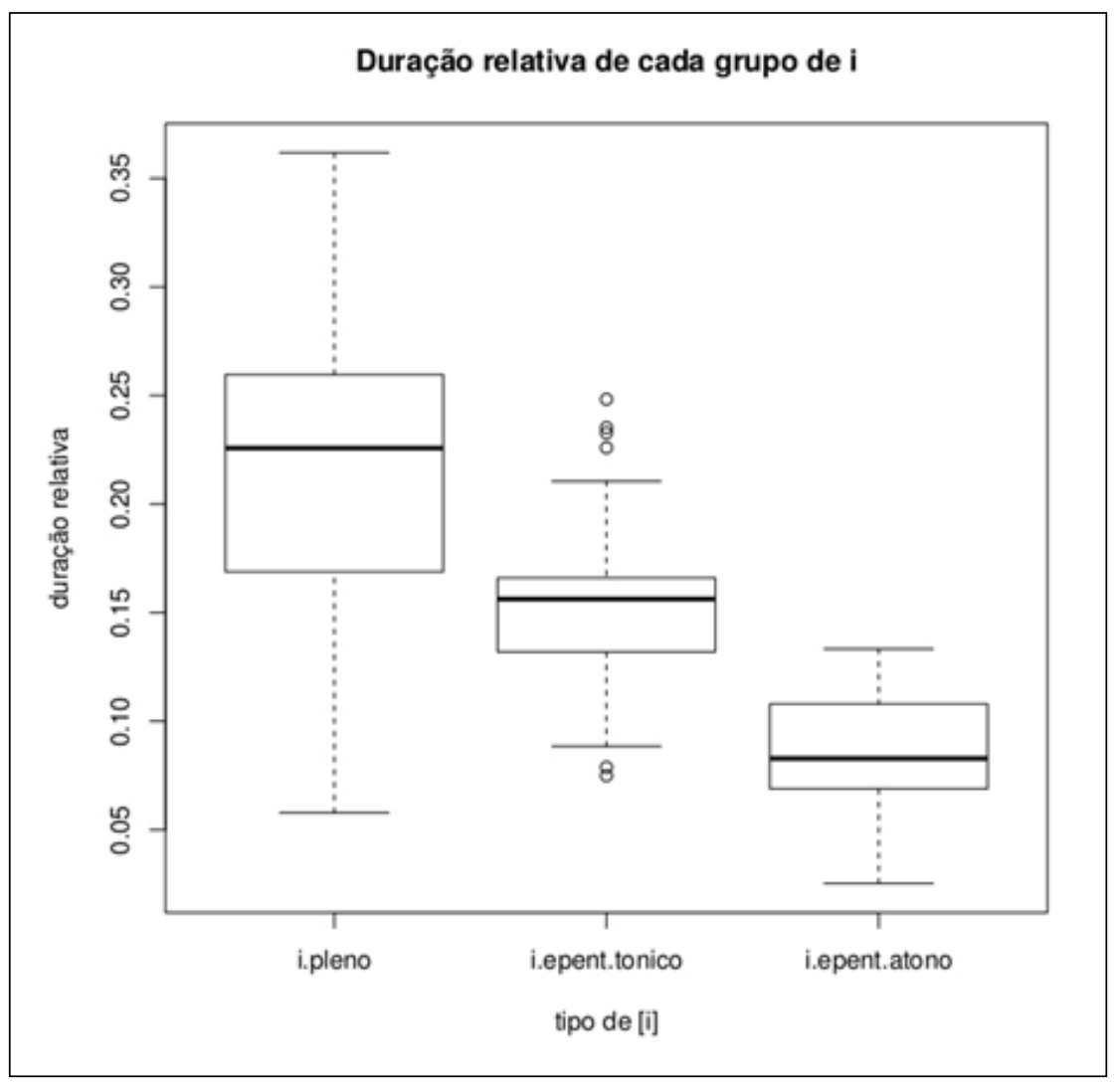

Como se pode observar na Fig. 3, os valores médios de duração das vogais epentéticas acentuadas são maiores que os das epentéticas átonas, mas inferiores aos das vogais [i] pleno. Essa tendência foi comprovada como estatisticamente significativa por meio de uma análise de variância, que apresentou um efeito significativo do grupo de [i] na duração da vogal $(\mathrm{F}=35,95, \mathrm{df}=2, \mathrm{p}<0,001)$. Também se mostrou significativo o efeito da palavra na duração da vogal $(\mathrm{F}=9,93, \mathrm{df}=6, \mathrm{p}<0,001)$, o que era esperado, uma vez que as palavras testadas diferiam em número de sílabas e segmentos sonoros com extensões diferentes. $O$ efeito da interação do grupo de [i] com a palavra sobre a duração da vogal apresentou um efeito de menor impacto $(\mathrm{F}=3,45, \mathrm{df}=3, \mathrm{p}=0,022)$, mas ainda assim considerável.

Os resultados obtidos neste estudo mostram que verbos apresentam comportamento diferente em relação à epêntese, apontando para a gradiência na implementação lexical do fe- 
nômeno, em conformidade com as propostas da Fonologia de Uso (BYBEE, 2001). Além disso, verificamos que a acentuação das vogais epentéticas é um fenômeno em franca atuação na variedade dialetal do português brasileiro avaliada, tendo apresentado altos índices de ocorrência para todas as palavras testadas. Quanto às características fonéticas das vogais epentéticas acentuadas, observamos que apresentam duração significativamente superior que as epentéticas átonas, mas significativamente inferior que as vogais [i] plenas. As vogais epentéticas acentuadas, portanto, encontram-se em posição intermediária entre as epentéticas átonas e as plenas, o que aponta para a gradiência fonética dos sons avaliados, como propõem os modelos multirrepresentacionais, e não uma oposição entre categorias discretas.

\section{Considerações finais}

Neste estudo, avaliamos o fenômeno de acentuação de vogais epentéticas e sugerimos que o mesmo dá suporte à interpretação de que as representações linguísticas são multidimensionais e operam em redes de relações.

Em uma perspectiva multirrepresentacional, a variação observada na língua entre [i] epentético $\sim$ [e], assim como a acentuação das vogais epentéticas, são indícios de que as representações são multidimensionais e de que padrões de alternância estabelecidos no sistema operam em redes de relações sonoras, morfológicas, etc., propiciando a emergência de padrões inovadores semelhantes, mas ocasionados por mecanismos distintos. Na perspectiva teórica adotada, a emergência de novos padrões sonoros na morfologia verbal da língua é interpretada como um reflexo da auto-organização gramatical que propicia a estabilidade e dinamicidade inerente às línguas naturais (BYBEE, 2010; ELLIS; LARSEN-FREEMAN, 2009).

Em pesquisas futuras, pretendemos abordar outras características fonéticas das vogais epentéticas acentuadas, como valores formânticos e intensidade, a fim de investigar mais aprofundadamente a gradiência fonética do fenômeno. Pretendemos ainda realizar análise de corpus para avaliar o papel desempenhado pelo uso linguístico na implementação dos fenômenos de epêntese e acentuação de vogais epentéticas. 


\section{REFERÊNCIAS BIBLIOGRÁFICAS}

BARLOW, M.; KEMMER, S. (Ed.). Usage-based models of language. Stanford: CSLI, 2000.

BISOL, L. O acento e o pé métrico binário. Cadernos de Estudos Lingüísticos, v. 22, p. 69-80, 1992.

BOERSMA, P.; WEENINK, D. 2013. Praat: doing phonetics by computer [Computer program]. Version 5.3.51, retrieved 2 June 2013 from http://www.praat.org/ .

BYBEE, J. Language, Usage and Cognition. Cambridge: Cambridge University Press, 2010.

BYBEE, J. Morphology: a study of the relation between meaning and form. Amsterdam: John Benjamins, 1985.

BYBEE, J. Phonology and Language Use. Cambridge: Cambridge University Press, 2001.

CÂMARA JUNIOR, J. Estrutura da língua portuguesa. 2. ed. Petrópolis: Vozes, 1970.

CANTONI, M. Universidade Federal de Minas Gerais. Categorização fonológica e representação mental: uma análise da alternância entre [ks] e [s] à luz de modelos de uso. 2009. Dissertação (mestrado) - Universidade Federal de Minas Gerais, Faculdade de Letras.

CANTONI, M.; CRISTÓFARO, T. Verbal Stress Assignment in Brazilian Portuguese and the Prosodic Interpretation of Segmental Sequences. In: CONFERENCE ON SPEECH PROSODY, 4th., 2008, Campinas. Proceedings... Campinas: IEL, 2008. p. 587-590.

COLLISCHONN, G. A epêntese vocálica no português do sul do Brasil. In: BISOL, L.; BRESCANCINI, C. (Ed.) Fonologia e variação: recortes do português brasileiro (VARSUL). Porto Alegre: EDIPUCRS, 2002.

CRISTÓFARO-SILVA, T.; ALMEIDA, L.; GUEDRI, C . Perda da marca de plural no português brasileiro: contribuições da Fonologia. Revista de Estudos da Linguagem, v. 15, p. 207-228, 2007.

DICANIO, C. General vowel acoustics script for Praat (versão 2.0). 2008, revisado em 2013. Disponível em http://www.haskins. yale.edu/staff/dicanio/scripts.html. Acesso: 21/01/2014. 
ELLIS, N.; LARSEN-FREEMAN, D. (Ed.). Language as a Complex Adaptive System. Oxford: Blackwell, 2009.

GELDER, T. van; PORT, R. It's about time: An overview of the dynamical approach to cognition. In: PORT, R.; GELDER, T. van (Ed.). Mind as Motion: Explorations in the Dynamics of Cognition. MIT: 1995. p. 1-43.

HALL, Nancy. Vowel Epenthesis. In: OOSTENDORP, Marc van et al. (eds.). The Blackwell companion to phonology. Malden, MA \& Oxford: Wiley-Blackwell, 2011. p. 1576-1596.

HAWKINS, S. Roles and representations of systematic fine phonetic detail in speech understanding. Journal of Phonetics, v. 31, p. 373-405, 2003.

JOHNSON, K. The auditory/perceptual basis for segmentation. OSU Working Papers in Linguistics, v. 50, p. 101-113, 1997.

JOHNSON, K.; MULLENIX, J. Complex representations used in speech processing: Overview of the book. In: JOHNSON, K.; MULLENIX, J. (Ed.). Talker variability in speech processing. San Diego: Academic Press, 1997. p. 1-8.

LENNES, M. Calculate-segment-durations (versão 12.3.2002). 2002. Disponível em http://www.linguistics.ucla.edu/faciliti/ facilities/acoustic/praat.html. Acesso: 05/02/2014.

PIERREHUMBERT, J. Exemplar dynamics: Word frequency, lenition and contrast. In: BYBEE, J.; HOPPER, P. (Ed.). Frequency and the emergence of linguistic structure. Amsterdam: John Benjamins, 2001a. p. 137-157.

PIERREHUMBERT, J. Stochastic phonology. GLOT, v. 5, n. 6, p. 1-13, $2001 b$.

PIERREHUMBERT, J.; BECKMAN, M.; LADD, R. Conceptual foundations of phonology as a laboratory science. In: BURTONROBERTS, N.; CARR, P.; DOCHERTY, G. (Ed.). Phonological Knowledge. Oxford: Oxford University Press, 2000. p. 273-303.

R Development Core Team. R: A Language and Environment for Statistical Computing. v. 2.13.0, Vienna - Áustria, 2011. Disponível em: <http://www.r-project.org/>. Acesso: 26/04/2011. 


\section{Abstract}

\section{A multirepresentational approach to epenthesis in Brazilian Portuguese.}

This paper presents a study on epenthesis in Brasilian Portuguese and its interaction with word stress. We focus on the gradient properties of epenthesis both in lexical, structural and phonetic terms. The main contribution of the present study is to offer an innovative approach to epenthesis, based on Laboratory Phonology and Multirepresentational Models. Data collected experimentally suggest that epenthesis and accentuation of epenthetic vowels are gradually implemented. The data analyzed show that stressed epenthetic vowels present duration patterns that lie in between the durations of regular vowels and unstressed epenthetic vowels, in a gradual way. We suggest that the results presented offer support to a multidimentional perspective to sound representations and that the linguistic system is organized through web relationships.

Key words: Epenthesis, Stress, Usage-Based Models, Brazilian Portuguese 